\title{
Adulterated Traditional-Herbal Medicinal Products and Its Safety Signals in Malaysia
}

\author{
Suriana Hanim Ariffin' \\ Izyan A Wahab iD ${ }^{2}$ \\ Yahaya Hassan ${ }^{3}$ \\ Mohd Shahezwan Abd Wahab ${ }^{3}$ \\ 'Pharmacy Enforcement Division, \\ National Pharmaceutical Regulatory \\ Agency, Petaling Jaya, 46200, Selangor, \\ Malaysia; ${ }^{2}$ Department of Clinical \\ Pharmacy and Pharmacy Practice, Faculty \\ of Pharmacy, University of Malaya, Kuala \\ Lumpur, 50603, Wilayah Persekutuan \\ Kuala Lumpur, Malaysia; ${ }^{3}$ Faculty of \\ Pharmacy, Universiti Teknologi MARA \\ (UiTM) Cawangan Selangor, Kampus \\ Puncak Alam, Puncak Alam, 42300, \\ Selangor, Malaysia
}

Background: Usage of traditional-herbal medicines (THM) for various illnesses has been increased around the world, so does the adulteration of these products with hazardous compounds. There are limited Malaysian data that have been published on the characteristics trend and adverse events associated with adulterated THM products.

Aim: This study described characteristics of adulterated THM products in Malaysia and aimed to quantify THM products' safety signals of adverse reactions (ARs).

Methods: THM products that were seized by Pharmacy Enforcement Division between 2008 and 2014 were extracted and analysed for 59,440 THM products. Of these, only 6452 THM products with complete information were included in the final analyses. Safety signalling tools were used to measure AR signals from AR reports obtained from the National Pharmaceutical Regulatory Agency Adverse Drug Reaction Database.

Results: More than half of adulterated THM products originated from countries outside of Malaysia, with the majority were from Indonesia. The most common claimed indication of adulterated THM products was for pain and fever relief, while steroids were the most common adulterant. AR signals were generated for cough and cold products for respiratory and thoracic disorders, weight-loss products for cardiac disorders, and women's health products for reproductive and breast disorders.

Conclusion: Health authorities from various fields can work collaboratively by implementing strategic actions that include the use of safety signalling tools to curb the increasing number of adulterated THM products in the Malaysian market.

Keywords: adulterated, safety, signal, traditional, products

\section{Introduction}

Traditional and herbal medicine (THM) is one of the oldest forms of healthcare in Malaysia. ${ }^{1}$ In a national survey, herbal medicines were found to be used by approximately $30 \%$ of Malaysians to maintain health. ${ }^{2}$ The common use of THM among Malaysians is usually influenced by the belief that these products are safer than modern medicines. Studies conducted in Malaysia showed that the public perceived THM have fewer side effects compared to modern medicines. ${ }^{3,4}$ Despite such belief, there has been an increased in warning issued by the local health authorities and in news coverage regarding the undesirable effects resulting from adulterated THM products.

Clinical trials are important to determine the efficacy and safety of conventional medicines. By law, conventional medicines must be tested through clinical trials and approved prior to their registration, marketing, and use by the public. However, THM products are not required to undergo any testing or clinical trials and the
Correspondence: Izyan A Wahab Department of Clinical Pharmacy and Pharmacy Practice, Faculty of Pharmacy, University of Malaya, Kuala Lumpur, 50603, Wilayah Persekutuan Kuala Lumpur, Malaysia

Tel +60379674909

Fax +60379674964

Email izyan@um.edu.my 
evidence of efficacy and safety are not required prior its registration and marketing. In Malaysia, THM products are easily accessed by the public and the demand for the products is increasing. The products can be obtained by the public from over the counter without a prescription and can be purchased online through various websites, online shopping platforms and social media.

Adulteration of THM product is a major concern as it is detrimental to the consumers. The most common adulterants found in THM products include sildenafil analogues in sexenhancement products, psychotropics, and sibutramine in weight-loss products, and anabolic steroids in dietary supplements. ${ }^{5,6}$ The National Regulatory Pharmaceutical Agency (NPRA) had circulated warnings about several THM products that have been identified as unregistered or adulterated. One example of a warning issued by the NPRA involved a THM product known as Majun Burung Unta that was advertised as a traditional product to treat various illnesses including muscle pain, heart problems, asthma, and period pain. ${ }^{7}$ However, several adverse effects such as weight gain, increased blood sugar level, and Cushing's syndrome have been reported from its use. Detailed investigations showed that the product was found to be adulterated with dexamethasone, a type of steroid which is listed as a controlled poison under the Malaysia Poison Act $1952 .{ }^{8}$ Due to the long-term adverse effect of steroids, a prolonged and inappropriate use of THM products that are adulterated with steroids can result in undesirable effects on the health of the consumers.

Strategic and systematic actions are needed to monitor the occurrence of adverse reactions (ARs) of THM products and to prevent future harm to the public especially when the access to the products cannot be limited. Few studies in China had attempted to use safety signalling tools to monitor THM products safety signal and are still refining their methods and databases. ${ }^{9,10}$ There are no local studies in Malaysia investigating the trend of adulterated THM products and the potential use of safety signalling tools for THM products. Therefore, this present study aims to identify the trend of seized adulterated THM products in Malaysia and to assess the safety signalling of ARs associated with THM products.

\section{Methods}

\section{Characteristics of Adulterated THM Products}

This was a retrospective study using the Cornerstone Data System under the Malaysia Pharmacy Enforcement, Pharmacy Services Division. Seized THM products were extracted from the Cornerstone Data System between January 2008 and December 2014 (7-year period). Only THM products that are complete with the following information were extracted and transferred into the data collection form:

1. Product's country origin.

2. The product's claimed indication. The claimed indication was cross-checked with the images of the products. The claimed indication was classified according to the list of indications outlined in the Drug Registration Guidance Document. ${ }^{11}$

3. The registration status. Registration of the product was checked and confirmed with the National Pharmaceutical Regulatory Agency (NPRA), Ministry of Health Malaysia.

4. Reported adulterants.

Validation of the extracted data was done by taking out $1 \%$ of the total data $(\mathrm{N}=595 / 59,440)$ from the Cornerstone Database System and clarified with the officer in charge of the database system. This is a validation practice undertaken periodically at NPRA by officer-in-charge to check and verify for data consistency relating to its structure, format and input variables. Descriptive statistical analysis was carried out using Microsoft Excel 2013 and IBM SPSS Version 20.

\section{Adverse Reaction (AR) Signal Generation for THM Products}

Reports of ARs from THM products between January 2008 and December 2014 (7-year period) were extracted from the NPRA Adverse Drug Reactions Database. Information regarding ARs was extracted and transferred into the data collection form. The extracted information included:

1. Product description including country of origin, indication, registration status, and dosage form.

2. Adverse reactions (ARs). The Medical Dictionary for Regulatory Activities (MEDRA) classification was used to classify ARs.

3. Characteristics of AR reporters such as gender and age.

Validation of data was done by taking out $1 \%$ of the total data (11/1102) from the Adverse Drug Reactions 
spontaneous data system and then clarified with the officer in charge of the database system. This is a validation practice undertaken periodically at NPRA by officer-incharge to check and verify for data consistency relating to its structure, format and input variables.

\section{Adverse Reaction (AR) Signalling Tools}

This study used the Proportional Reporting Ratio (PRR) and Reporting Odds Ratio (ROR) to generate AR signals for THM products in Malaysia. These signalling tools are being used by many health authorities around the world to generate AR signals. $^{12}$ The tools were found to be valid, reliable, and effective for signalling ARs of medicines and THM products. ${ }^{12,13}$ The PRR compares the reporting rate of the suspected medicine and adverse effects with reporting rates of other medicines and adverse effects reports in the spontaneous reporting database. PRR was used in this study to compare the reporting rate of the THM product of interest and its adverse effects in the spontaneous reporting database. ROR is calculated by a division sum of the numerator consists of the number of cases where a THM product was used, and a specific AR was reported, divided by the number of cases in which all other THM was used for the specific reported AR. The denominator consists of the number of cases using suspected THM product of interest with all other reported ARs, divided by all other THM products with all other reported ARs.

An AR signal is considered to have been generated when the threshold criteria related to the PRR are exceeded. These criteria are: 1) PRR value is 2 or more, 2) three or more case reports for a suspected THM product and the ARs, and 3) Yates chi-square value of 4 or more. For ROR, a 95\% confidence interval of the lower limit of 1 or more is considered as an AR signal. ${ }^{12}$ PRR and ROR directly measure the strength of associations; therefore, higher PRR and ROR values indicate a strong association. Tables 1 and 2 show the information used to support the calculation for the two methods. Counts of reports were obtained from the spontaneous reporting database and used as the unit of analysis in calculating the PRR and ROR statistics.

\section{Ethical Approval}

This study was approved by the National Pharmaceutical Regulatory Agency and the Medical Research and Ethics' Committee (NMRR-16-1577-32462).
Table I $2 \times 2$ Table of the Disproportionality Analysis of PRR and ROR

\begin{tabular}{|l|c|c|c|}
\hline $\begin{array}{l}\text { Traditional Herbal } \\
\text { Medicines (THMs) }\end{array}$ & $\begin{array}{c}\text { Specific } \\
\text { Adverse } \\
\text { Reactions }\end{array}$ & $\begin{array}{c}\text { All Other } \\
\text { Adverse } \\
\text { Reactions }\end{array}$ & Total \\
\hline Specific THM & A & B & A + B \\
\hline All other THMs & C & D & C + D \\
\hline
\end{tabular}

Notes: $A=$ case reports of $\mathrm{THM}$ associated with specific adverse reactions; $B=$ case reports of THM associated with all other adverse reactions; $C=$ all other THMs associated with specific adverse reactions; $D=$ all other THMs associated with all other adverse reactions.

Table 2 Pharmaco-Surveillance Methods, Information Used to Generate Signal and the Threshold for ADR Signal

\begin{tabular}{|l|l|l|}
\hline Method & \multicolumn{1}{|l|}{ Information Used } & \multicolumn{1}{c|}{$\begin{array}{c}\text { Criteria for Signal } \\
\text { Detection }\end{array}$} \\
\hline PRR & {$[A /(A+B)) /(C /(C+D)]$} & $P R R \geq 2, A \geq 3, x^{2} \geq 4$ \\
\hline$R O R$ & $(A / B) /(C / D)$ & Lower limit of $95 \% C I \geq I, A \geq 2$ \\
\hline
\end{tabular}

Abbreviations: $\mathrm{x}^{2}$, Yates chi-square; $\mathrm{Cl}$, confidence interval.

\section{Results}

\section{Characteristics of Adulterated THM Products Seized in Malaysia and THM Adverse Reaction (AR) Reports}

A total of 59,440 of THM products were seized in Malaysia that were due to several offences from 2008 to 2014. Out of all seized THM products, $11 \%(6452 / 58,440)$ were identified as adulterated products with complete information for analysis. Of these, 55\% $(n=3549 / 6452)$ were products manufactured overseas whereas $45 \%$ $(\mathrm{n}=2903 / 6452)$ were products manufactured locally (Table 3). THM products manufactured overseas were mainly originated from Indonesia $(45.7 \%, \mathrm{n}=2947 / 6452)$, China $(5.5 \%, \mathrm{n}=355 / 6452)$, North America $(2.4 \%, \mathrm{n}=153$ / 6452), and Middle East $(0.7 \%, n=47 / 6452)$. The most common THM products were used for pain and fever (53.6\%, $\mathrm{n}=3461 / 6452), \quad$ sex-enhancement $\quad(26.4 \%$, $\mathrm{n}=1702 / 6452)$, and weight-loss $(8.2 \%, \mathrm{n}=529 / 6452)$ (Table 3). All seized products were identified to be unregistered under the health authority.

The majority of THM products were reported to be adulterated with a single adulterant $(95.3 \%, \mathrm{n}=6147 / 6452)$. Steroids were the most commonly identified adulterant among the THM products $(47.8 \%, \mathrm{n}=3083)$, followed by phosphodiesterase inhibitors $(25.8 \%, \quad n=1663 / 6452)$, 
Table 3 Characteristics of Adulterated THM Products Seized in Malaysia $(n=6542)$ and THM AR Reports $(n=900)$

\begin{tabular}{|c|c|c|c|c|c|}
\hline \multirow[t]{2}{*}{ Adulterated THM Products Characteristics } & \multicolumn{2}{|c|}{$\begin{array}{l}\text { Total THM } \\
\text { Products }\end{array}$} & \multirow[t]{2}{*}{ THM AR Reports Characteristics } & \multicolumn{2}{|c|}{$\begin{array}{l}\text { Total THM AR } \\
\text { Reports }\end{array}$} \\
\hline & $\mathbf{N}$ & $\%^{\mathbf{a}}$ & & $\mathbf{N}$ & $\%^{\mathbf{b}}$ \\
\hline Origin of Products & & & Origin of Products & & \\
\hline Local & 2903 & 45 & Local & 640 & 71 \\
\hline International & 3639 & 55 & International & 260 & 29 \\
\hline Indonesia & 2947 & 45 & - & - & - \\
\hline China & 355 & 6 & - & - & - \\
\hline North America & 153 & 2 & - & - & - \\
\hline Middle East & 47 & 1 & - & - & - \\
\hline Other countries & 47 & 1 & - & - & - \\
\hline Product Claimed Indication & & & Product Claimed Indication & & \\
\hline Pain and Fever & 3461 & 54 & General Health & 366 & 41 \\
\hline Sex Enhancement & 1702 & 26 & Pain and fever & 179 & 20 \\
\hline Weight-loss & 529 & 8 & Slimming & 62 & 7 \\
\hline Cough and Cold & 366 & 6 & Cough and cold & 59 & 7 \\
\hline General Health Maintenance & 107 & 2 & Blood and body fluid & 47 & 5 \\
\hline Women's Health & 94 & 1 & Women's health & 41 & 4.5 \\
\hline Men's Health & 94 & I & Digestive system & 36 & 4 \\
\hline Skin and External Usage & 65 & 0.9 & Diabetes & 28 & 3 \\
\hline Other indications & 34 & 0.5 & Other indications & 82 & 9.1 \\
\hline Product Registration Status & & & Product Registration Status & & \\
\hline Registered & - & 0 & Registered & 641 & 71 \\
\hline Not Registered & 6452 & 100 & Not Registered & 259 & 29 \\
\hline Adulterants & & & Product Dosage Form & & \\
\hline Single adulterant & 6417 & 95 & Oral & 886 & 98 \\
\hline Multiple adulterant & 305 & 5 & Topical & 14 & 2 \\
\hline & & & $\begin{array}{l}\text { Demographic of reporters } \\
\text { Age (year) }\end{array}$ & & \\
\hline & & & $0-14$ & 16 & 2 \\
\hline & & & $15-64$ & 679 & 75 \\
\hline & & & $>65$ & 205 & 23 \\
\hline & & & Gender & & \\
\hline & & & Female & 511 & 57 \\
\hline & & & Male & 370 & 41 \\
\hline & & & Unknown & 19 & 2 \\
\hline
\end{tabular}

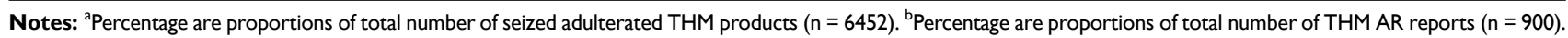
Abbreviations: THM, traditional herbal medicine; AR, Adverse Reaction.

monoamine reuptake inhibitors $(8.2 \%, \mathrm{n}=531 / 6452)$, nonsteroidal anti-inflammatory drugs (NSAIDS) (5.6\%, $\mathrm{N}=364 / 6452)$, and antihistamines $(2.2 \%, \mathrm{n}=141 / 6452)$ (Table 4).

For THM AR reports, a total of 1102 AR reports had been submitted to the Malaysian Adverse Drug Reactions Advisory Drug Committee between the year 2008 and 2014. Of these, 202 (18.3\%) reports were excluded from analysis because they were related to food-drug interphase products. In total, $900 \mathrm{AR}$ reports were analyzed in this study. About $70 \%$ of the AR reports involved local and registered THM products with the majority were marketed in oral dosage forms (Table 3). THM products that were marketed for promoting general health had the highest frequency of ARs $(40.7 \%, n=366 / 900)$, followed by products claimed to alleviate pain and fever $(19.9 \%, \mathrm{n}=179$ / $900)$, promote weight-loss $(6.9 \%, n=62 / 900)$, treat cough and cold $(6.6 \%, n=59 / 900)$, and promote women's health 
Table 4 Summary of the Common Single and Multiple Adulterants Found in Adulterated THM Products

\begin{tabular}{|c|c|c|}
\hline & \multicolumn{2}{|c|}{$\begin{array}{l}\text { Total Adulterated THM } \\
\text { Products }(n=6452)\end{array}$} \\
\hline & Number & Percentage $\left(\%^{\mathrm{a}}\right)$ \\
\hline Single Adulterants $(n=64 \mid 7)$ & & \\
\hline Steroid & 3083 & 47.78 \\
\hline Phosphodiesterase inhibitor & 1663 & 25.77 \\
\hline Monoamine reuptake inhibitor & 531 & 8.23 \\
\hline $\begin{array}{l}\text { Non-steroidal anti-inflammatory } \\
\text { drugs (NSAIDS) }\end{array}$ & 364 & 5.64 \\
\hline Antihistamine & $|4|$ & 2.19 \\
\hline Sex Hormone & 92 & 1.43 \\
\hline Sodium Channel Blocker & 91 & I.4I \\
\hline N- Methyl-D- Aspartate & 43 & 0.67 \\
\hline Antagonist & & \\
\hline Alpha Beta-Adrenergic Agonist & 24 & 0.39 \\
\hline Tyrosinase Enzymes Inhibitor & 24 & 0.39 \\
\hline Antifungal & 22 & 0.39 \\
\hline Others & 339 & 5.25 \\
\hline Multiple Adulterants $(n=305)$ & & \\
\hline Steroid/NSAIDS & 123 & 1.91 \\
\hline Antihistamine/Steroid & 23 & 0.36 \\
\hline NSAIDS/ NSAIDS & 23 & 0.36 \\
\hline $\begin{array}{l}\text { Antihistamine/N- Methyl-D- } \\
\text { Aspartate Antagonist }\end{array}$ & 19 & 0.29 \\
\hline $\begin{array}{l}\text { Steroid/ Phosphodiesterase } \\
\text { Inhibitor }\end{array}$ & 18 & 0.28 \\
\hline $\begin{array}{l}\text { Alpha Beta-Adrenergic Agonist/ } \\
\text { Non-Selective Phosphodiesterase } \\
\text { Inhibitor }\end{array}$ & 13 & 0.20 \\
\hline $\begin{array}{l}\text { Phosphodiesterase Inhibitor/ } \\
\text { Phosphodiesterase Inhibitor }\end{array}$ & 12 & 0.19 \\
\hline Steroid/Steroid & 10 & 0.15 \\
\hline Others & 64 & 0.9 \\
\hline
\end{tabular}

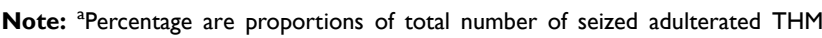
products $(n=6452)$.

Abbreviations: THM, traditional herbal medicine; NSAIDS, non-steroidal antiinflammatory drugs.

$(4.6 \%, n=41 / 900)$ (Table 3). Women and those with age in the range between 15 and 64 years were the most frequent THM AR reporters.

\section{AR Signals for THM Products}

The most frequently reported AR was hepatobiliary disorders $(17.2 \%, n=155 / 900)$, followed by blood and lymphatic disorders $(16.6 \%, \mathrm{n}=149 / 900)$, renal and urinary disorders (15.1\%, $\mathrm{n}=136 / 900)$, skin disorders $(11.7 \%, \mathrm{n}=105 / 900)$, and gastrointestinal disorders $(7.6 \%, \mathrm{n}=68 / 900)$. AR signals from both PRR and ROR were generated for: 1) respiratory and thoracic disorders and THM products indicated for the treatment of cough and cold, 2) cardiac disorders for THM products indicated for promoting weight-loss, and 3) reproductive and breast disorders for THM products indicated for promoting women's health (Table 5).

\section{Discussion}

This study shows that steroids and NSAIDS were common adulterants among seized adulterated THM products used for treating pain and fever. Consistently, pain and fever were among the most frequent indications for THM products reported for AR in Malaysia (Table 3). This finding is consistent with studies undertaken in other Asian countries and South Africa. ${ }^{14,15}$ Our findings showed that there is a demand for THM products to relieve pain and fever among Malaysians and suggesting that many people are self-medicating themselves using THM for common illnesses. The perception that THM products are safer than conventional modern medicines ${ }^{3,4}$ may promote selfmedication using THM among the public. Furthermore, due to the easy access and increased availability of the products in the market, self-medication with THM could be done without much restrictions.

The present study showed that both databases (spontaneous AR and adulterated THM products databases) have the potential to complement each other as a surveillance system for serious AR relating to THM products. For instance, the cardiac disorder safety signal found for THM products marketed to promote weight loss (Table 5) as identified from the spontaneous AR database was found to be consistent with the identification of monoamine reuptake compound as an adulterant in those THM products (Table 4).

Sibutramine, a monoreuptake inhibitor, was previously approved for weight-loss but was withdrawn from the global market in 2010 because its cardiovascular risk outweighs its modest weight-loss benefits. ${ }^{16}$ However, the substance has been incorporated illegally in many THM products worldwide. Malaysia has been regarded as a country in Asia with high obesity rate where in 2015, the National Health and Morbidity Surveys revealed that $30 \%$ of the population was overweight and $17.7 \%$ were categorised as obese. ${ }^{17}$ Due to the unavailability of legitimate weight loss product, it is possible that the public turn to THM to promote weight-loss. This is evident by the widespread sale of this product in both the retail and online markets. The high prevalence of self-medication using natural products for weight-loss was also observed 
Table 5 PRR and ROR Signals for THM Products

\begin{tabular}{|l|c|c|c|}
\hline THM Products' Claimed Indication & Adverse Event Based on SOC & PRR & ROR \\
\hline Cough and flu & Respiratory and thoracic disorders & PRR: 3.65 I4 & ROR: 4.3938, \\
& & AR report: 59 & $95 \%$ Cl: 0.1162 \\
& & Yates chi-square: 9.238 I & \\
\hline Weight-loss & Cardiac disorders & PRR: 4.2963 & ROR: 5.4949, \\
& & AR report:62 & $95 \%$ Cl: 0.1452 \\
& & Yates chi-square: 14.2844 & \\
\hline Women's health & Reproductive system and breast disorders & PRR: 14.1316 & ROR: 33.8289, \\
& & AR report: 41 & $95 \%$ Cl: 0.8185 \\
& & Yates chi-square: 22.6668 & \\
\hline
\end{tabular}

Abbreviations: THM, traditional herbal medicine; SOC, system organ class; PRR, proportional reporting ratio; ROR, reporting odds ratio.

in a study in Mexico. ${ }^{18}$ Despite the safety issue related to weight-loss THM products, the products have been frequently advertised in women's magazines. ${ }^{19}$ Control of advertisement of THM products with its testimonials in magazines and websites can be tightened by health authorities through public awareness campaign on prohibited and illegal claims and provide a public channel for easy reporting for the authorities to take action.

THM products indicated for sex-enhancement were found to be the second most common adulterated THM products that were seized in this study. Similarly, the United States Food and Drug Administration (FDA) has reported that phosphodiesterase inhibitors are the most common adulterant found in adulterated herbal medicines. ${ }^{20}$ A press release by the Malaysian Minister of Health has also highlighted the concern on the use of THM products that are adulterated with phosphodiesterase inhibitors. ${ }^{21}$ The products may cause unsafe reduction in blood pressure in men and especially among those who are on antihypertensive agents. The high prevalence of erectile dysfunction (ED) among Asian men, low socioeconomic and with comorbidities $^{22}$ may contribute to the high demand for THM products for sexual enhancement perceived as inexpensive and safe products.

Similar to pharmaceutical drugs, due to the chemical moieties present in THM, the products would undergo similar biological processes in the human body ie, administration, distribution, metabolism, and excretion. ${ }^{23}$ Therefore, when used inappropriately, THM products may produce toxicity similar to that observed in pharmaceutical drugs such as nephrotoxicity, hepatotoxicity and neurotoxicity. In this study, the most common AR that was associated with THM use was hepatotoxicity. Our finding should raise concern since THM products are highly sought by the public and its use is not regulated. There is a need to increase awareness among the public about safety issues of THM products especially if they are adulterated.

Safety signals generated for "cough and flu" THM products for respiratory and thoracic disorder adverse event and "women's health" THM products for reproductive disorders adverse event could be due to false positive signals that arise from the correlation of the indication and the adverse effects. False positive signals can occur when a medication or in this case a THM product has an indication for the identified adverse event. However, the sensitivity and specificity of signalling tools used in this study are found high in previous studies. ${ }^{24}$ Hence, there is also a possibility that the safety signals are true positive signals. ${ }^{25}$ This finding needs further investigation.

In Malaysia, the Pharmacy Enforcement Division is located at the national entry points to control the importation of pharmaceutical products. This division also acts as technical advisors for the Royal Malaysian Customs (RMC) regarding pharmaceutical products. ${ }^{26}$ These authorities play important roles in controlling the influx of THM products into the country. Since more than half (55\%) of the adulterated THM products identified in this study originated from other countries, mainly from Indonesia and China, there is a need for a stricter entry requirement by the authorities for THM products into the country. The authorities could pay additional attention of THM products that are indicated for general health, pain and fever, sex-enhancement, weightloss, and cough and flu since these products are the most common type of THM to be adulterated.

Regulatory control can be a significant intervention in controlling THM product industry. There are several regulatory controls that have been implemented to monitor THM products in other countries. In the European countries, other 
than declaring data of the ingredients, source, dose, potency, and suggested indication to obtain approval for sale, all THM products must comply with domestic processes that must demonstrate adequate safety and efficacy. ${ }^{27}$ In Malaysia, all THM products must be registered with the Drug Control Authority prior to marketing. ${ }^{28}$ The Drug Control Authority only registers products that meet the standards established by the National Pharmaceutical Regulatory Agency. Nevertheless, despite such regulations adulterated THM products are still prevalently available. This is evident by the fact that none of the seized THM products identified in this study was registered. Our results suggest that there is a gap in the measures taken to curb the distribution of unregistered THM products by the relevant authorities. It is therefore recommended for the Malaysian regulatory agency to consider working collaboratively with different authorities such as the post-marketing surveillance unit to optimise AR safety signal detection and to adopt relevant and effective regulations of other countries. These measures may help in minimizing the manufacturing and marketing of unregistered and adulterated THM products thus ensuring the safety of Malaysian THM products consumers. Another recent measures to control THM products in the market is by having separate authenticators that exercise reliable identification, standardisation and authentication of these products. ${ }^{29}$ Strategic and collaborative approaches among authenticators may be the key solution to control the risk associated with increasing demand and supply of THM products in Malaysia.

\section{Limitations}

Several limitations should be taken into account when interpreting the results of this study. This study did not directly measure safety signals from the identified adulterant found in the seized THM products; hence, the direct impact of the adulterants could not be directly interpreted as the cause of the reported ARs. However, the nature of occurrence of the ARs is assumed to be due to similar chemical compounds as the adulterants for the claimed indication of the THM products. Secondly, underreporting is expected for spontaneous reporting database especially for THM products; hence, the safety signal results found in this study may not reflect the true magnitude of safety of THM products.

\section{Conclusion}

Within seven years of data, majority of seized adulterated THM products were originated from neighbouring countries outside Malaysia for pain and fever indication, sex-stimulant and body slimming products. The most common adulterant found in these products are steroids, phosphodiesterase inhibitor and monoamine reuptake inhibitor. When using safety signalling tools applied on adverse event reporting database, signals were generated for cough and cold products for respiratory and thoracic disorders adverse event, weightloss products for cardiac disorders adverse event, and women's health products for reproductive and breast disorders adverse event. This study finding suggests that the authorities at the national entry point of international products need to be more cautious on selected priority of THM products entering from neighbouring countries. Strict controlling of importation, distribution and sales of steroids substances should also be considered. Safety signalling tools can be used to complement continuous monitoring of adverse events associated with THM products.

\section{Acknowledgment}

We would like to thank Malaysia Ministry of Health $(\mathrm{MOH})$ Pharmacy Enforcement Division and National Pharmaceutical Regulatory Agency (NPRA) for providing data used in this study. The study results, discussion and conclusion are from authors and do not represent the opinion of $\mathrm{MOH}$.

\section{Disclosure}

The authors declare that they did not receive funding nor have no other potential conflicts of interest for this work.

\section{References}

1. Thomas S, Beh L, Nordin RB. Health care delivery in Malaysia: changes, challenges and champions. J Public Health Afr. 2011;2:e23. doi:10.4081/jphia.2011.e23

2. Siti Z, Tahir A, Farah AI, et al. Use of traditional and complementary medicine in Malaysia: a baseline study. Complementary Ther Med. 2009;17:292-299. doi:10.1016/j.ctim.2009.04.002

3. Mitha S, Nagarajan V, Babar M, Siddiqui MJA, Jamshed SQ. Reasons of using complementary and alternative medicines (CAM) among elderly Malaysians of Kuala Lumpur and Selangor states: an exploratory study. $J$ Young Pharm. 2013;5(2):50-53. doi:10.1016/j. jyp.2013.05.002

4. Silvanathan S, Low BS. Current public awareness on the safety of traditional and complementary medicines (T\&CM) in Malaysia. Eur J Integr Med. 2014;7:184-189. doi:10.1016/j.eujim.2014.12.003

5. Reepmeyer JC, Woodruff JT. Use of liquid chromatography-mass spectrometry and a chemical cleavage reaction for the structure elucidation of a new sildenafil analogue detected as an adulterant in an herbal dietary supplement. J Pharm Biomed Anal. 2007;44:887-893. doi:10.1016/j.jpba.2007.04.011

6. De Carvalho LM, Martini M, Moreira APL, et al. Presence of synthetic pharmaceuticals as adulterants in slimming phytotherapeutic formulations and their analytical determination. For Sci Int. 2011;204:6-12.

7. Majun Burung Unta: amaran Kepada Orang Awam Mengenai Pengambilan Produk Tidak Berdaftar (National Pharmaceutical Regulatory Agency); 2014. Available from: npra.gov.my. Accessed February 8, 2021. 
8. Laws of Malaysia Act 366. Poison Act 1952; 1989.

9. Wei JX, Wang J, Zhu YX, Sun J, Xu HM, Li M. Traditional Chinese medicine pharmacovigilance in signal detection: decision tree-based data classification. BMC Med Inform Decis Mak. 2018;18:19. doi:10.1186/s12911-018-0599-5

10. Yongyang X, Danhui Y, Mingyan X. Quantitative pharmacovigilance modelling for TCM injections adverse event reporting. J Pharmacovigilance. 2014;2:2.

11. National Pharmaceutical Regulatory Agency. Drug Registration Guidance Document. Second Edition. Malaysia; 2016. Available from:https://www.npra.gov.my/index.php/en/drug-registrationguidance-documents-drgd-e-book. Accessed February 8, 2021.

12. van Puijenbroek EP, Bate A, Leufkens HGM, Lindquist M, Orre R, Egberts ACG. A comparison of measures of disproportionality for signal detection in spontaneous reporting systems for adverse drug reactions. Pharmacoepidemiol Drug Saf. 2002;11:3-10. doi:10.1002/pds.668

13. Wechwithan S, Suwankesawong W, Sornsrivichai V, McNeil EB, Jiraphongsa C, Chongsuvivatwong V. Signal detection for Thai traditional medicine: examination of national pharmacovigilance data using reporting odds ratio and reported population attributable risk. Regul Toxicol Pharmacol. 2014;70:407-412. doi:10.1016/j.yrtph.2014.06.007

14. Park HJ, Cho SH, Lee JH, et al. Screening for Corticosteroid Adulterants in Korean Herbal Medicines. J for Sci. 2016;61:226-229.

15. Peltzer K. Utilization and Practice of Traditional/Complementary/ Alternative Medicine (TM/CAM) In South Africa. Afr J Tradit Complement Altern Med. 2009;6:175-185.

16. James WP, Caterson ID, Coutinho W, et al.; Renz CL SCOUT Investigators. Effect of sibutramine on cardiovascular outcomes in overweight and obese subjects. N Engl J Med. 2010;363:905-917. doi:10.1056/NEJMoa1003114

17. Institute for Public Health (IPH). National health and morbidity survey 2015 (NHMS 2015). Vol. II: non-communicable diseases, risk factors \& other health problems. Kuala Lumpur: Ministry of Health Malaysia; 2015. ISBN 978-983-2387-23-7.

18. Alonso-Castro AJ, Ruiz-Padilla AJ, Ramírez-Morales MA, et al. Self-treatment with herbal products for weight-loss among overweight and obese subjects from central Mexico. J Ethnopharmacol. 2019;24:21-26. doi:10.1016/j.jep.2019.01.003

19. Hassali M, Saleem F, Aljadhey H, Khan T. Evaluating the content of advertisements for dietary supplements in Malaysian women's magazines. Drug Info J. 2012;46:723-728. doi:10.1177/0092861512457777
20. Wired. Dietary supplements can contain viagra, steroids, or worse. United States of America; 2018. Available from: https://www.wired. $\mathrm{com} /$ story/dietary-supplements-can-contain-viagra-steroids-or-worse /. Accessed February 8, 2021.

21. Adulteration in Traditional Medicine Products. MyHealth, Ministry of Health, Malaysia. Adulteration in traditional medicine products PORTAL MyHEALTH; 2017. Accessed February 8, 2021.

22. Irfan M, Hussain NHN, Noor NM, Mohamed M, Sidi H, Ismail SB. Epidemiology of male sexual dysfunction in Asian and European regions: a systematic review. Am J Men's Health. 2020;14(4):1-40. doi: $10.1177 / 1557988320937200$

23. García-Cortés M, Stephens C, Lucena MI, Fernández-Castañer A, Andrade RJ. Causality assessment methods in drug induced liver injury: strengths and weaknesses. J Hepatol. 2011;55(3):683-691. doi:10.1016/j.jhep.2011.02.007

24. Wahab IA, Pratt NL, Kalisch LM, Roughead EE. Sequence symmetry analysis and disproportionality analyses: what percentage of adverse drug reaction do they signal? Adv Pharmacoepidemiol Drug Saf. 2013;2(4):1-5.

25. Tang L, Lee AH, Binns CW, Hui YV, Yau KKW. Consumption of Chinese herbal medicines during pregnancy and postpartum: a prospective cohort study in China. Midwifery. 2016;34:205-210. doi:10.1016/j.midw.2015.11.010

26. Ting CY, Ting H, Soh YC, Aaj AH, Lee KS. Awareness of custom officers on counterfeit pharmaceutical products and the roles of pharmacy enforcement officers. J Young Pharm. 2017;9:258-262. doi:10.5530/jyp.2017.9.50

27. Enioutina EY, Salis ER, Job KM, Gubarev MI, Krepkova LV, Sherwin CM. Herbal Medicines: challenges in the modern world. Status and current directions of complementary and alternative herbal medicine worldwide. Exp Rev Clin Pharmacol. 2017;10:327-338.

28. National Pharmaceutical Regulatory Agency (NPRA)/ FAQ/ Product Registration. Available from: http://npra.moh.gov.my/index.php/faq/ product-registration. Accessed February 8, 2021.

29. Sadgrove NJ. Honest nutraceuticals, cosmetics, therapies, and foods (NCTFs): standardization and safety of natural products, Critical Reviews in Food Science and Nutrition; 2021:1-16.
Drug, Healthcare and Patient Safety

\section{Publish your work in this journal}

Drug, Healthcare and Patient Safety is an international, peer-reviewed open-access journal exploring patient safety issues in the healthcare continuum from diagnostic and screening interventions through to treatment, drug therapy and surgery. The journal is characterized by the rapid reporting of reviews, original research, clinical, epidemiological and post-marketing surveillance studies, risk management, health

\section{Dovepress}

literacy and educational programs across all areas of healthcare delivery. The manuscript management system is completely online and includes a very quick and fair peer-review system. Visit http://www.dovepress.com/testimonials.php to read real quotes from published authors. 